UCRL-JC-128366 Rev 2

PREPRINT

\title{
Design of a Distributed Radiator Target for Inertial Fusion Driven from Two Sides with Heavy Ion Beams
}

\author{
M. Tabak \\ D. Callahan-Miller
}

This paper was prepared for submittal to the 39th Annual Meeting of the American Physical Society

Division of Plasma Physics

Pittsburgh, PA

Novem ber 17-21, 1997

November 10, 1997

This is a preprint of a paper intended for publication in a journal or proceed ings. Since changes may be made before publication, this preprint is made available with the understanding that it will not be cited or reproduced without the permission of the author. 
Design of a distributed radiator target for inertial fusion driven from two sides with heavy ion beams

Max Tabak and Debra Callahan-Miller, Lawrence Livermore National Laboratory, Livermore, CA

\section{$\underline{\text { Abstract }}$}

We describe the status of a distributed radiator heavy ion target design. In integrated calculations this target ignited and produced 390-430 MJ of yield when driven with 5.8-6.5 MJ of 3-4 GeV $\mathrm{Pb}$ ions. The target has cylindrical symmetry with disk endplates. The ions uniformly illuminate these endplates in a $5 \mathrm{~mm}$ radius spot. We discuss the considerations which led to this design together with some previously unused design features: low density hohlraum walls in approximate pressure balance with internal low- $Z$ fill materials, radiation symmetry determined by the position of the radiator materials and particle ranges, and early time pressure symmetry possibly influenced by radiation shims. We discuss how this target scales to lower input energy or to lower beam power. Variant designs with more realistic beam focusing strategies are also discussed. We show the tradeoffs required for targets which accept higher particle energies.

PACS numbers:44.40.+a,52.40.Mj,52.58.Hm

proofs to:

Max Tabak

L-477

Lawrence Livermore National Laboratory 
P.O. Box 5808

Livermore,California 94550

USA

email: tabak1@llnl.gov

fax:(510)-423-9208 


\section{Introduction}

Heavy ion accelerators are a leading candidate as a driver for inertial fusion energy(IFE) because of their high efficiency, $\eta,(25-40 \%)$ and robustness. Issues for accelerators such as beam brightness and cost remain and continue to be addressed. We present the first target design and integrated (from ion beam deposition to fusion yield) calculation, using the code LASNEX $^{1}$, of a target driven by heavy ion beams producing high enough gain, $G$, to be adequate for IFE. We describe a radiation-driven heavy ion fusion (HIF) target illuminated from two directions by ion beams in which the radiation is generated in nearly $4 \pi$ steradians surrounding the implosion system (capsule). Reactor designs using thick fluid first walls such as HYLIFE ${ }^{2}$ prefer a small envelope for the illuminating beams. It is difficult to form multiple entrance ports in arbitrary locations from fluid walls. Capsules directly driven with laser or ion beams have beam ports covering a significant fraction of $4 \pi$ steradians. The laser beams driving indirectly driven target design for the National Ignition Facility(NIF) also are directed from $a^{-\infty}$ significant fraction of $4 \pi$ steradians.

The target described here uses a converter distributed in solid angle to achieve uniform capsule illumination with ion beams coming from a small solid angle. Converters (or radiators) absorb the ion beam energy, heat and then radiate this energy as $\mathrm{x}$-rays to the hohlraum and implosion system(capsule). The calculations show that this design, when driven with 6.5 
$\mathrm{MJ}$ of 3-4 GeV lead ions can produce $430 \mathrm{MJ}$ of thermonuclear yield. The gain of 66 produces $\eta \mathrm{G}>16$, which is more than adequate for energy applications.

The design study focused on providing adequate implosion symmetry. We relied on previous results ${ }^{(3)}$ in choosing a capsule to have adequate hydrodynamic implosion stability and ignition margin. As seen in Table I, the HIF capsule shown in figure 1 had somewhat more conservative parameters than a leading candidate design for the National Ignition Facility(NIF). Experiments at the NIF will more precisely define the implosion requirements, surface finish and symmetry requirements of the HIF targets.

\section{Issues in symmetry control}

The high frequency spatial modes can be reduced by hohlraum re-radiation and transport from the hohlraum wall to the capsule surface. $(3,4,5,6)$ However, the low order modes must be cancelled by accurate placement of radiator material. As a guide to the design we note that for a spherical hohlraum the proper radiator positions, to zero all modes $P_{7}$ and below, would be the zeroes of $\mathrm{P}_{4}$, the fourth Legendre polynomial, and the relative intensities would be given by the associated Gaussian weights ${ }^{(4,7)}$. A cylinder requires slightly different beam placement. ${ }^{(5)}$ The difficulty in practice is to maintain the locations and intensities of the radiating regions while avoiding the movement of obscuring materials as a function of time. 
Unlike laser driven systems, the electron and radiation temperatures are approximately equal in regions driven by ion beams and containing high- $Z$ materials. Therefore, energy transport via electrons is much less important here than in the laser case where electron temperatures in the low- $Z$ material surrounding the capsule can be an order of magnitude higher than radiation temperatures. In steady state, neglecting conduction, a radiator will come to a temperature where the net radiation out of a region equals the ion beam energy deposited there. The spatial density of radiation emission is then proportional to the collisional energy loss of the ion beam. It therefore depends most strongly on the local electron density, the beam current, the particle energy and the charge state of the incident and target ions.

The total range of the particles depends on the material temperature through the fraction of electrons which are bound in the target material. It depends also on the material density through the ionization state and logarithmically through the stopping power per free electron. However, the material densities can change by orders of magnitude during the implosion time for materials which start at full density. We chose the column density in the high$\mathrm{Z}$ endplates so that they would be a few tens of optical depths thick at the peak operating temperature. Larger column densities would capture too murch beam energy and thinner endplates result in excess radiation loss. A normal density foil would be about 10 microns thick. During the implosion time the heated foil would expand $1-2 \mathrm{~mm}$, a reduction in density of a factor 100 . Figure 2 shows that for $3.5 \mathrm{GeV} \mathrm{Pb}$ ions the stopping power depends more on density than on electron temperature. The stopping power of gold at $300 \mathrm{eV}$ at 0.1 $\mathrm{gm} / \mathrm{cm}^{3}$ is twice that of gold at normal density. Beginning with full density materials, we would expect significant range shortening and an associated 
symmetry swing. Therefore, we will use an initial density of approximately $1 \%$ of normal density to reduce this symmetry swing.

If the hohlraum wall intrudes into the beam path, it will be difficult to heat the region above the capsule, causing a swing in the $\mathrm{P}_{2}$ component of the radiation flux driving the capsule. We can control the radial position of the hohlraum wall by tamping it with low $\mathrm{Z}$ material at no energy cost. Figure 3 shows the results of two 1-D cylindrical simulations driven with the same radiation temperature and ending with the high- $Z$ low- $Z$ interface at approximately the same radius. One initial state was a high density wall at large radius with little tamping while the other had more low- $Z$ tamping, a lower density case and a smaller initial radius. The tamped calculation required $15 \%$ less energy to support the radiation temperature than the untamped design because it had less wall area to heat.

W $\mathrm{e}^{8}$ need a very low density internal region to avoid an early time asynchrony caused by the time required to burn through higher density $\left(10^{-}\right.$ $2 \mathrm{gm} / \mathrm{cm}^{3}$ ) material. Figure 4 shows the ratio of the measured $\mathrm{P}_{4}$ flux asymmetry on a spherical monitor surface to that imposed in a source for a variety of carbon fill densities varying from $10^{-3} \mathrm{gm} / \mathrm{cm}^{3}$ to $10^{-2} \mathrm{gm} / \mathrm{cm}^{3}$. The monitor radius is $40 \%$ of the source radius of $1 \mathrm{~cm}$. The radiation temperature of the source ramps from 0 to $100 \mathrm{eV}$ in 5 nanoseconds. We can see that at early times there is amplification of the imposed asymmetry as the radiation wave burns through the foam. The two peaks in the asymmetry correspond to burning through the $\mathrm{L}$ and $\mathrm{K}$ shells of carbon, respectively. At late times the symmetry relaxes to the vacuum value, but at early times the asymmetry can imprint the capsule. 


\section{Hydrodynamic coupling issues}

We want to avoid coupling hydrodynamically between the hohlraum wall and/or the converters with the capsule. This can ruin the implosion symmetry or adiabat. This can occur if we use high density $(>0.1 \mathrm{gm} / \mathrm{cc})$ low $\mathrm{Z}$ material as a converter with sufficient column density to stop the beam. This density raised to the temperature required to drive the implosion system will produce pressures much larger than the ablation pressure. This pressure is converted to kinetic energy as the converter blows in, but the pressure is recaptured when the converter stagnates on the imploding capsule. This is illustrated in figure 5 for a spherically symmetric target where the pressure as a function of radius is plotted at several times. The initial converter density is $0.25 \mathrm{gm} / \mathrm{cm}^{-3}$. At the end of the foot of the radiation pulse the stagnation pressure is larger than the ablation pressure.

These effects can be mitigated by using low density converters( as suggested by the range shortening argument), an appreciable fraction of the range in high or mid $\mathrm{Z}$ materials( with low soundspeeds) and aspherical hohlraums. Aspherical hohlraums with beams parallel to the long axis provide longer pathlengths and thus allow lower converter densities than do sphericāi designs. They also have a smaller column density of converter imploding towards the capsule. In addition, shields to stop ions past their Bragg peaks can accomodated to eliminate another source of preheat. The following section describes how our design solution integrates the ingredients discussed above. 
The point design is shown in Fig.6. The ion beam has an intensity profile uniform to $5 \mathrm{~mm}$ and zero beyond. The beam is parallel to the symmetry axis. The beam spot is larger than in earlier end radiator designs ${ }^{(9)}$. We chose a lower particle range for this larger spot to maintain the radiation converter heat capacity comparable to those of the earlier end radiator designs. Emittance-dominated beams with equal normalized emittance have focal spot areas which scale as $\mathrm{v}^{-2}$ while the particle range scales as $\mathrm{v}^{3}$, where $\mathrm{v}$ is the particle speed. Recent reaction chamber transport calculations $(10)$ indicate that if there is a remnant chamber gas density as large as $10^{13}$ atoms/cc (consistent with molten salt protection schemes ${ }^{(2)}$ ) space charge neutralization of the beam in the chamber is both required and possible even for $10 \mathrm{GeV}$. Detailed PIC chamber calculations have verified acceptable spot sizes for these lower energy beams.

The ends of the cylinder are divided into three sections: a region thick to ions at all times extending from the symmetry axis to just outside the capsule radius, a region thick to ions at late times extending to radius, $r_{2}$, and a region thin to ions at all times extending to the cylindrical radius, $r_{c y l}$. The inner $-\circ$ region(beam block) is designed so that no ions directly couple to the capsule. This would otherwise cause early time imprinting. Twenty five percent of the incoming energy is absorbed by this beam block and does not contribute to the implosion(but is included in the $6.5 \mathrm{MJ}$ of ion beam energy). This percentage depends strongly on focusing geometry and beam shape. Targets suitable for other beam geometries reducing the $25 \%$ loss in the central region are discussed below. 
The hohlraum case material was chosen to be a 50-50 alloy of gold and gadolinium. Gd has high opacity in photon energy bands where gold has low opacity. This alloy has been shown ${ }^{(12)}$ to have $50 \%$ higher opacity than pure $\mathrm{Au}$ and to reduce radiative wall losses by about $15 \%$.

The internal void required for good radiation transport does not pressure balance the converter material. The amount of this material in the beam path first decreases as the material expands into the interior void then increases as ablated capsule material pushes the material back into the beam path. We chose low density gold in the equatorial plane because its low sound speed would minimize this effect. An acceptable alternate is a low density $\mathrm{CH}_{2}$ foam seeded with a high- $Z$ material. By adjusting relative densities, compositions or interface shapes, we have some control of this converter density as a function of time.

The thin mid- $Z$ layers lining the end disks serve two purposes. They tamp the motion of high- $Z$ material, keeping it from occluding the converter regions. Mid-Z materials were chosen because they lose much of their opacity as they heat past $200 \mathrm{eV}$. Hence, as the range shortens in the high- $\mathrm{Z}$ case, the material between the ion heated region and the capsule becomes more transparent.

Figure 7 from an earlier design shows that we can tune the $P_{2}$ asymmetry by changing $r_{2}$ and hence the relative importance of emission over the ball to emission from the ends of the hohlraum. The large change in symmetry at 30 
ns is due to range shortening as the hohlraum temperature increases from the foot temperature to the peak. As shown in Figure 8 which shows this temperature together with the ion power, the temperature rises quickly. We compensate for this by increasing the ion beam particle energy to 3.5 or $4 \mathrm{GeV}$ near 30 nanoseconds. Technologically, this can be accomplished by utilizing multiple beamlines operating at different particle energies. An energychanging strategy similar to this was originally proposed by G.O.Allshouse for light ion target designs.

The $\mathrm{P}_{4}$ asymmetry can be varied by changing the hohlraum aspect ratio. Increasing the length of hohlraum while decreasing its radius will increase the positive $\mathrm{P}_{4}$ contribution and cancel the negative $\mathrm{P}_{4}$ contribution coming from large radius and large axial position. Figure 9 shows that at 31 nanoseconds the regions of ion power deposition density are near the zeroes of $\mathrm{P}_{4}$. The peak deposition occurs in the beam block, where it is not visible to the capsule. The source near the endplate is offset to compensate the cold spot near the beam block.

Another strategy, not used in this point design but successful in alternate calculations, deposits a thin $(<1$ micrometer thick) iron coating on the part of the capsule receiving excess flux at early times. The effect of this layer vanishes as it ablates and moves a capsule diameter. However, during this period the capsule implodes and afterward radiation transport smoothing $(6,3)$ reduces the effect of the $\mathrm{P}_{4}$ asymmetry. 
Future designs can be simplified: regions $L$ and $M$ can have the same density; regions $\mathrm{O}, \mathrm{N}$ and $\mathrm{G}$ can be replaced with $\mathrm{CH}_{2}$ foils; the low density high- $\mathrm{Z}$ materials can be replaced with foils which are allowed to expand under the action of a low intensity ion beam until the pressure-balanced low density regime is reached. Foams of the required density have been used in applications as far away as the planet Mars. The low density gold/gadolinium regions may be replaced by sets of foils or wires possibly spaced with very low density aerogels. These changes would require some retuning, but should not change the target operation in any essential way. For example, the lowest density gold region has been successfully replaced by a high- $Z$ seeded foam in other calculations.

\section{Capsule performance}

Figure 10 shows the coefficients of $\mathrm{P}_{2}, \mathrm{P}_{4}$ and $\mathrm{P}_{6}$ in an angular expansion of the time integral of the pressure driving the capsule as a function of time. Figures $11 \mathrm{a}$ and $11 \mathrm{~b}$ show the relative density and temperature isocontours in the compressed core close to ignition time and demonstrate the adequate symmetry of the implosion. The capsule ignited and produced $430 \mathrm{MJ}$. This was the first integrated calculation of an inertial fusion target demonstrating adequate gain, 66, for fusion energy applications.

Design consistent with multiple Gaussian beams 
The particular top hat transverse spatial profile for the incident ion beam discussed above may not be realistic. Furthermore, it is likely that the total power will be supplied in a number of beams incident from directions not parallel to the hohlraum symmetry axis. In this section we describe a design ${ }^{14}$ which includes this additional degree of realism.

The spots were 2-D Gaussians in which $95 \%$ of the charge was included in ellipses with semiaxes of 1.8 and $4.15 \mathrm{~mm}$. The area of these spots is the same as circles of radius $2.7 \mathrm{~mm}$. Strong focusing produces such elliptical beams through the accelerating structure. Using these elliptical spots ${ }^{15}$ allows us to form an annular illumination structure with 2.4 times the individual beam array required for circular beam spots. Eight prepulse(6 degree half-angle about symmetry axis, $3 \mathrm{GeV}, 0.8-1.05 \mathrm{MJ})$ and 16 main pulse(12 degrees, $4 \mathrm{GeV}$, 1.89-2.24) beams were incident from each side. These parameters are consistent with an accelerator systems study ${ }^{16}$. When these beams are symmetrically overlaid on the target endcap, the prepulse had a $-1.6 \%$ azimuthal asymmetry in $m=8$, while the main pulse asymmetry was $0.06 \%$ in $m=16$. These high order asymmetries should be efficiently smoothed by radiation transport. We modeled the targets assuming azimuthal symmetry using the illumination geometry shown in Figure 12. $5.87 \mathrm{MJ}$ (including $10 \%$ in the wings of the Gaussian which misses) was incident, yielding $402 \mathrm{MJ}$ and gain 68 .

Work in progress:relaxing accelerator requirements 
Here we discuss three different target directions which may relax accelerator requirements: lowering required intensity, increasing the particle energy and reducing the energy total energy required for ignition. In order to relax the focusing and peak power requirements on the ion beam, we sought target designs with $210 \mathrm{eV}$ peak radiation drive temperature. For capsules absorbing $1 \mathrm{MJ}$, this temperature is consistent with Lindl's ${ }^{3}$ estimate for hydrodynamic stability. The hohlraum is then $20 \%$ larger in linear dimension than that shown above with beam power $30 \%$ lower as shown in Figure 13 together with the produced radiation temperature. A 1D capsule implosion produced 380 $\mathrm{MJ}$ while the integrated 2D calculation has produced only $5 \mathrm{MJ}$ for $6.5 \mathrm{MJ}$ of ion energy in a top hat spatial profile. Some retuning should recover the $1 \mathrm{D}$ results.

For some types of accelerators, higher particle energy is preferable. The particle energy can be increased with acceptable increase in total incident energy. Approximately $1 \mathrm{MJ}$ of the incident energy is resident as heat capacity in the converters. In this region of particle energy, $\mathrm{T}$ : [3-10 GeV], the particle range scales as $T^{1.5}$. Therefore, tripling the particle range would increase the required beam energy to $8 \mathrm{MJ}$ for $8 \mathrm{GeV}$ ions. The resulting gain, 50, is still acceptable. An integrated calculation has already demonstrated capsule yield of $350 \mathrm{MJ}$ for $6.25 \mathrm{MJ}$ with $5.5 \mathrm{GeV}$ incident lead ions.

In order to peg the low energy part of the gain curve we have studied ignition scale targets. The ignition capsule driven at $250 \mathrm{eV}$ absorbed about $220 \mathrm{~kJ}$ and yielded $19 \mathrm{MJ}$ in 1D. NIF designs have been proposed which absorb about $90 \mathrm{~kJ}$. An energy scale for the ignition design was set by linearly scaling the hohlraum dimensions in the ratio $0.123 / 0.234$ between the outer radii of the 
ignition capsule and the capsule of Figure 1. The scaled integrated 2D calculation which was driven with $1.9 \mathrm{MJ}$ of $3-4 \mathrm{GeV} \mathrm{Pb}$ ions had a peak hohlraum temperature of $285 \mathrm{eV}$, substantially higher than required.

\section{$\underline{\text { Summary }}$}

Integrated calculations have demonstrated more than adequate gain for inertial fusion energy with target geometries consistent with liquid wall reactor protection schemes. That the gain is greater than 65 at $6 \mathrm{MJ}$ input energy implies $\eta G$ is greater than 16. Two focusing strategies have spot sizes consistent with neutralized chamber transport. The target uses pressured balanced walls/converters to produce a quasi-static geometry. We are scaling the target designs to lower drive energies, lower radiation temperatures and higher particle energies.

The authors thank E.M.Campbell, Grant Logan and Alex Friedman for encouragement, Useful discussions with George Zimmerman, Darwin Ho, Roger Bangerter and Judy Harte are acknowledged. Work performed under the auspices of the U.S.Department of Energy by Lawrence Livermore Notional Laboratory under Contract W-7405-ENG-48.

\section{References}

1. G.B.Zimmerman and W.B.Kruer,Comments Plasma Phys. Controlled Fusion $2(1975) 85$.

2. R.W.Moir,Physics of Plasmas 2,6(1995)2447. 
3. J.D.Lindl,Physics of Plasmas 2,11(1995)3933 and S.W.Haan,et.al.,Physics of Plasmas 2,6(1995)2480.

4. M.Tabak,"A Relatively Simple Model of Symmetrization in Hohlraums,"in Laser Program Annual Report,1986/87, Lawrence Livermore National Laboratory,Livermore,CA.,UCRL-50055-86/87,pp2-50-2-55(unpublished).

5. M.Tabak,"Symmetry properties of reactor scale hohlraums,"in Laser Program Annual Report,1986/87,Lawrence Livermore National Laboratory, Livermore, CA.,UCRL-50055-86/87,pp2-169-2-182(unpublished).

6. S.W.Haan,"Radiation transport between concentric spheres, "Lawrence Livermore National Laboratory, Livermore,CA.,COPD 83-64,1983(unpublished).

7. See National Technical Information Service Document No. DE86005297 (J.W.Mark, "Reduction of deposition asymmetries in directly driven ion beam and laser targets,"1984 Laser Program Annual Report, Lawrence Livermore National Laboratory, Livermore, CA.,UCRL-50021-84,pp 3-24-3-28). Copies may be obtained from the National Technical Information Service, Springfield,VA 22161.

8. D.Callahan-Miller and M.Tabak, Bulletin of the American Physical Society $41,7(1996) 1390$ and in preparation for publication.

9. D.D-M Ho,Harte,J.A. and Tabak,M.,Nuclear Fusion 35,9(1995)1125 and D.D-M Ho,Lindl,J.D. and Tabak,M., Nuclear Fusion 34, 8 (1994) 1081.

10. D.A.Callahan,Fusion Engineering and Design 32,(1996)441.

11. D.A. Callahan-Miller,private communication(1997).

12. T.J.Orzechowski,et.al., Physical Review Letters 77,17(1996)3545.

13. G.O.Allshouse,et.al.,in preparation for publication, and R.E.Olson. and J.J.McFarlane,Lasers and Particle Beams 15,3(1997)461.

14. D.Callahan-Miller and M.Tabak,in preparation.

15. J.Kwan,private communication(1997). 
16. W.Meier,R.O.Bangerter and A.Faltens,"An integrated Systems Model for Heavy Ion Drivers,"Proceedings of the 12th International Symposium on Heavy Ion Inertial Fusion,Heidelberg, 1997.

17. J.T.Larsen and S.M.Lane, Journal of Quantitative Spectroscopy and Radiative Transfer 51,1(1994)179. 


$\begin{array}{lll} & \text { NIF } & \text { HIF } \\ \text { Absorbed Energy(MJ) } & 0.15 & 1 \\ \text { Yield(MJ) } & 15 & 430 \\ \text { Convergence ratio } & 36 & 27 \\ \text { In-flight aspect ratio } & 45 & 40 \\ \text { Peak density }(\mathrm{gm} / \mathrm{cc}) & 1200 & 650 \\ \text { Peak radiation } & 300 & 260 \\ \text { temperature(eV) } & \\ \text { Table I. Comparison of NIF and HIF capsule parameters as calculated by the } \\ \text { program HYADES }{ }^{17} \text {. }\end{array}$


Figure captions

1. Pie diagram of spherically symmetric implosion capsule.

2. Range of $3.5 \mathrm{GeV} \mathrm{Pb}$ ions in $\mathrm{Pb}$ (upper curves) and $\mathrm{CH}_{2}$ with 100 (solid) and $300 \mathrm{eV}$ (dashed) electron temperatures for ranges of densities.

3. Initial(dashed lines) and final(solid lines) densities profiles for two DT filled $\mathrm{Au}$ cylinders with initial ratios of DT and Au densities driven by the same radiation source. The arrows at the bottom mark the interface positions. 4. Smoothing function for $\mathrm{P}_{4}$ perturbation in fluence between source and radius 0.4 of source radius for various carbon fill densities as functions of time:A, $1 \mathrm{mg} / \mathrm{cc} ; \mathrm{B}, 2.5 \mathrm{mg} / \mathrm{cc} ; \mathrm{C}, 5 \mathrm{mg} / \mathrm{cc} ; \mathrm{D}, 10 \mathrm{mg} / \mathrm{cc}$.

5. Pressure as a function of radius at several times for a spherical ion beam target. The time associated with each curve increases from $\mathrm{A}$ to $\mathrm{E}$.

6.Quadrant of initial hohlraum configuration. The hohlraum is reflectionsymmetric about $\mathrm{z}=0$ and rotationally symmetric about $\mathrm{r}=0$. The figure is cut off at an axial position of $1 \mathrm{~cm}$. The case continues to $1.8 \mathrm{~cm}$. The gridding is shown with dashed lines. Region boundaries are marked with thick solid lines. The regions are labeled by capital letters denoting compositions and density in $\mathrm{gm} / \mathrm{cc}: \mathrm{A}, \mathrm{Au}_{0.5} \mathrm{Gd}_{0.5}, 0.1 ; \mathrm{B}, \mathrm{Au}_{0.5} \mathrm{Gd}_{0.5}, 13.520$ micrometers thick; C, $\mathrm{Au}_{0.5} \mathrm{Gd}_{0.5}$, 0.26; D, $\mathrm{Au}_{0.5} \mathrm{Gd}_{0.5}, 0.5 ; \mathrm{E}, \mathrm{Au}_{0.5} \mathrm{Gd}_{0.5}, 1.0 ; \mathrm{F}, \mathrm{Au}_{0.5} \mathrm{Gd}_{0.5}, 0.1 ; \mathrm{G}, \mathrm{Al}, 0.055 ; \mathrm{H}, \mathrm{D}_{2}--0.001 ; \mathrm{I}$, $\mathrm{Au}, 0.023 ; \mathrm{J}, \mathrm{CH}_{2}, 0.011 ; \mathrm{K}, \mathrm{CH}_{2} \mathrm{Au}_{0.03}, 0.011 ; \mathrm{L}, \mathrm{Fe}, 0.064 ; \mathrm{M}, \mathrm{Fe}, 0.083 ; \mathrm{N}, \mathrm{CH}_{2}, 0.03 ; \mathrm{O}$, $\mathrm{CH}_{2} \mathrm{Au}_{0.03}, 0.03$.

7. Second Legendre coefficients of the incident fluence measured near a sphere of radius $0.255 \mathrm{~cm}$ for three hohlraums which differ only in the radius dividing the thin endwall from the moderate endwall by .

8. Average radiation temperature measured at a spherical radius of $3.4 \mathrm{~mm}$ together with incident beam power as functions of time. 
9. Ion power deposition density together with positions of the zeroes of the second and fourth Legendre polynomials.

10. Coefficients of $\mathrm{P}_{2}, \mathrm{P}_{4}, \mathrm{P}_{6}$ in an angular expansion of the time integral of the peak pressure measured near the ablation front.

11.a) Density/max(density) isocontours near ignition time;b) ion temperature $/$ max(temperature) isocontours near ignition time.

12. Annular illumination geometry with elliptical beams. The dashed lines denote the prepulse;solid lines, the main pulse. The thickest lines denote the beam centroids.

13. Radiation temperature $(\mathrm{keV})$ and beam power $\left(10^{15} \mathrm{~W}\right)$ as functions of time for low temperature design. 


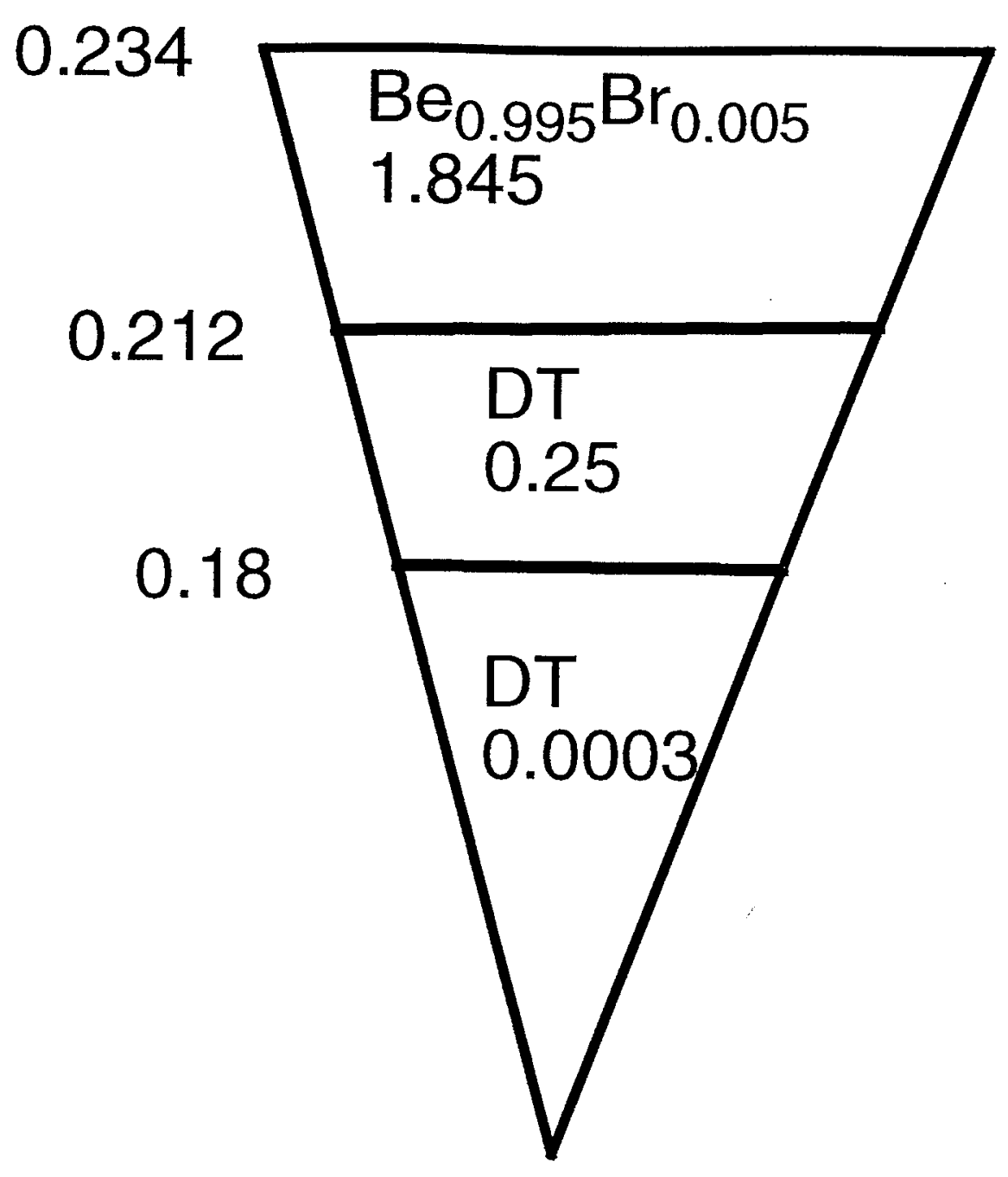

Tabak Phys. of Plasur Fig. I 


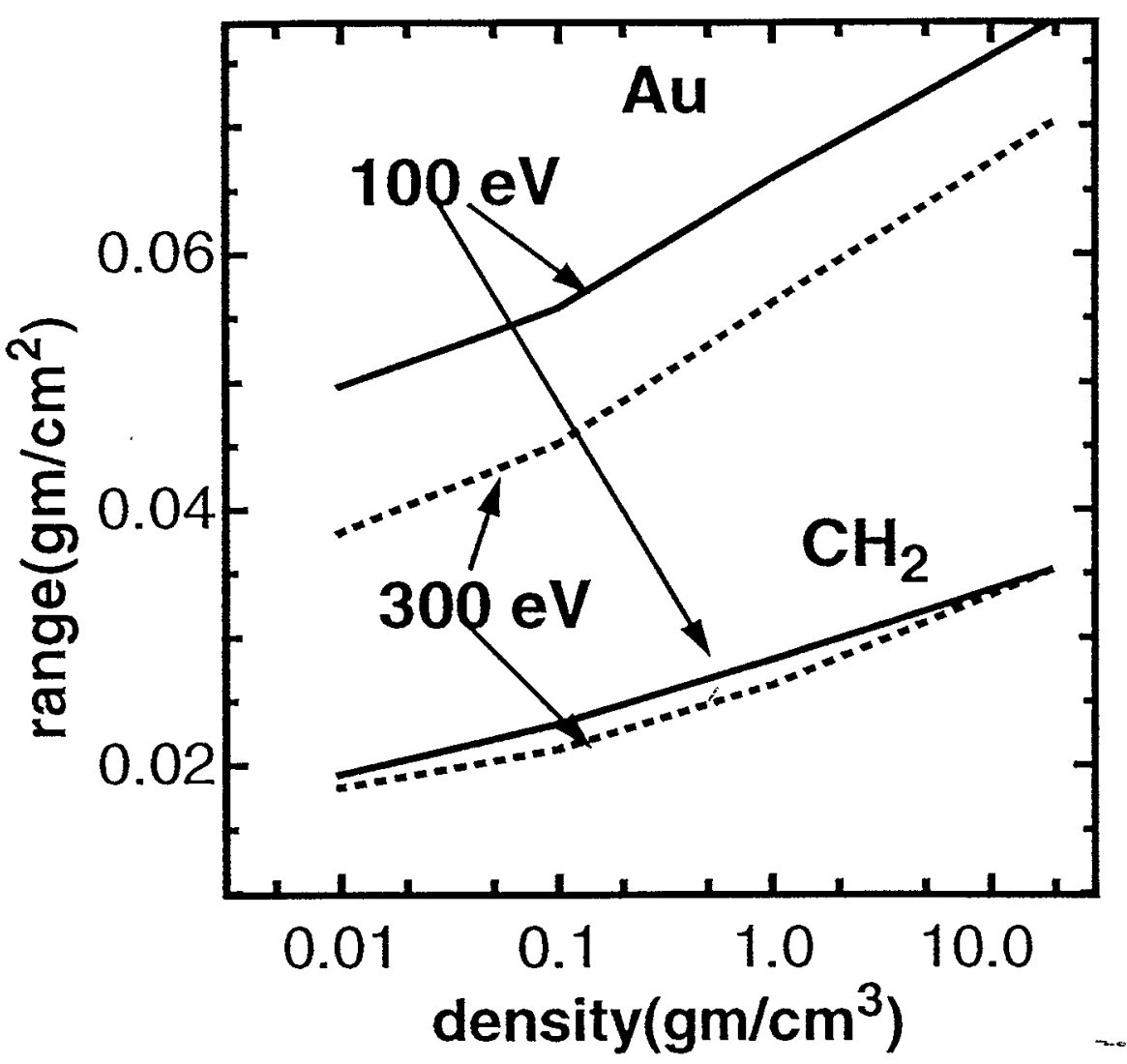

Tahak Pkys. of Alasu, Fig. 2 


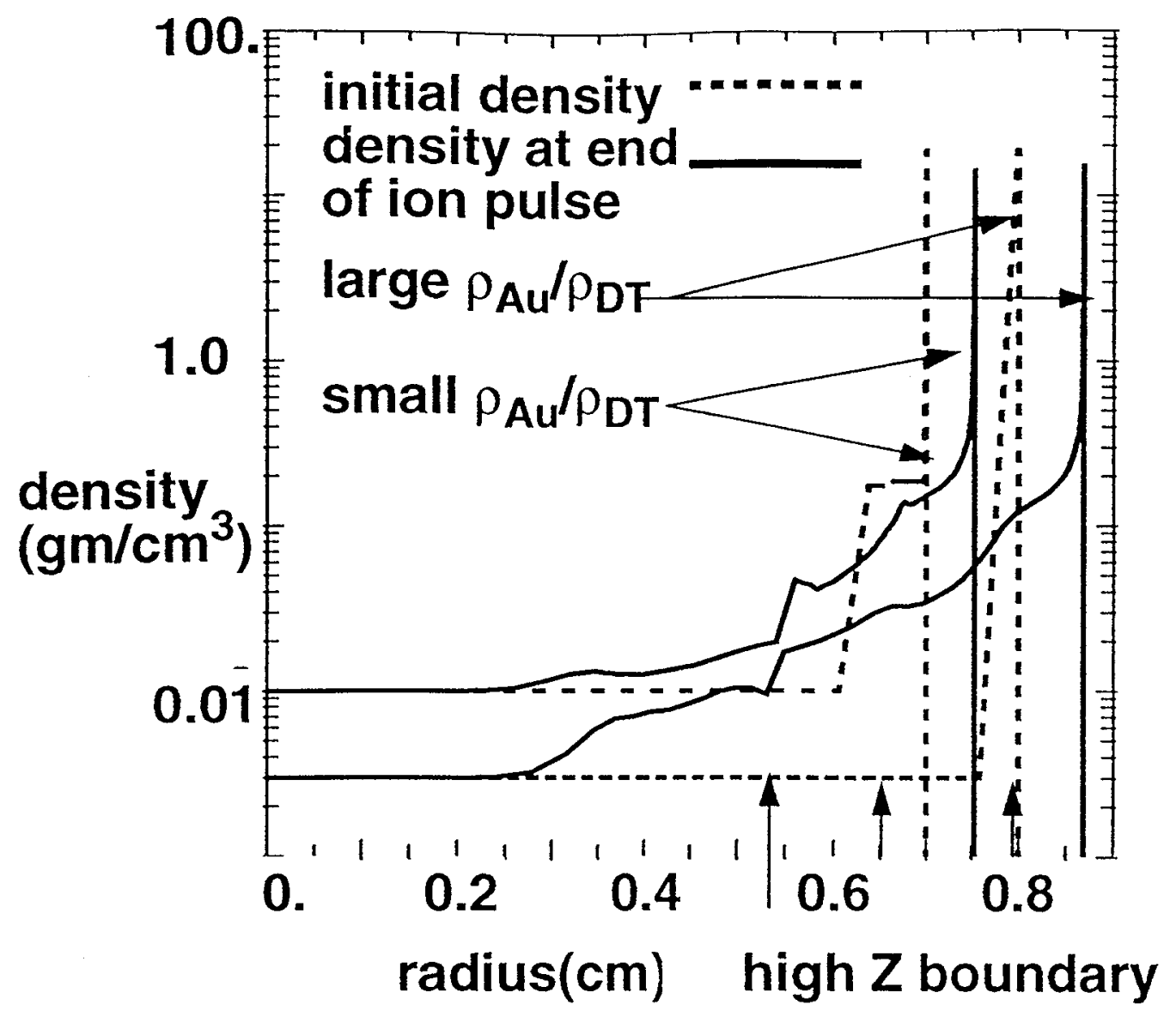

Taball Phas of Plasha Fig. 3 

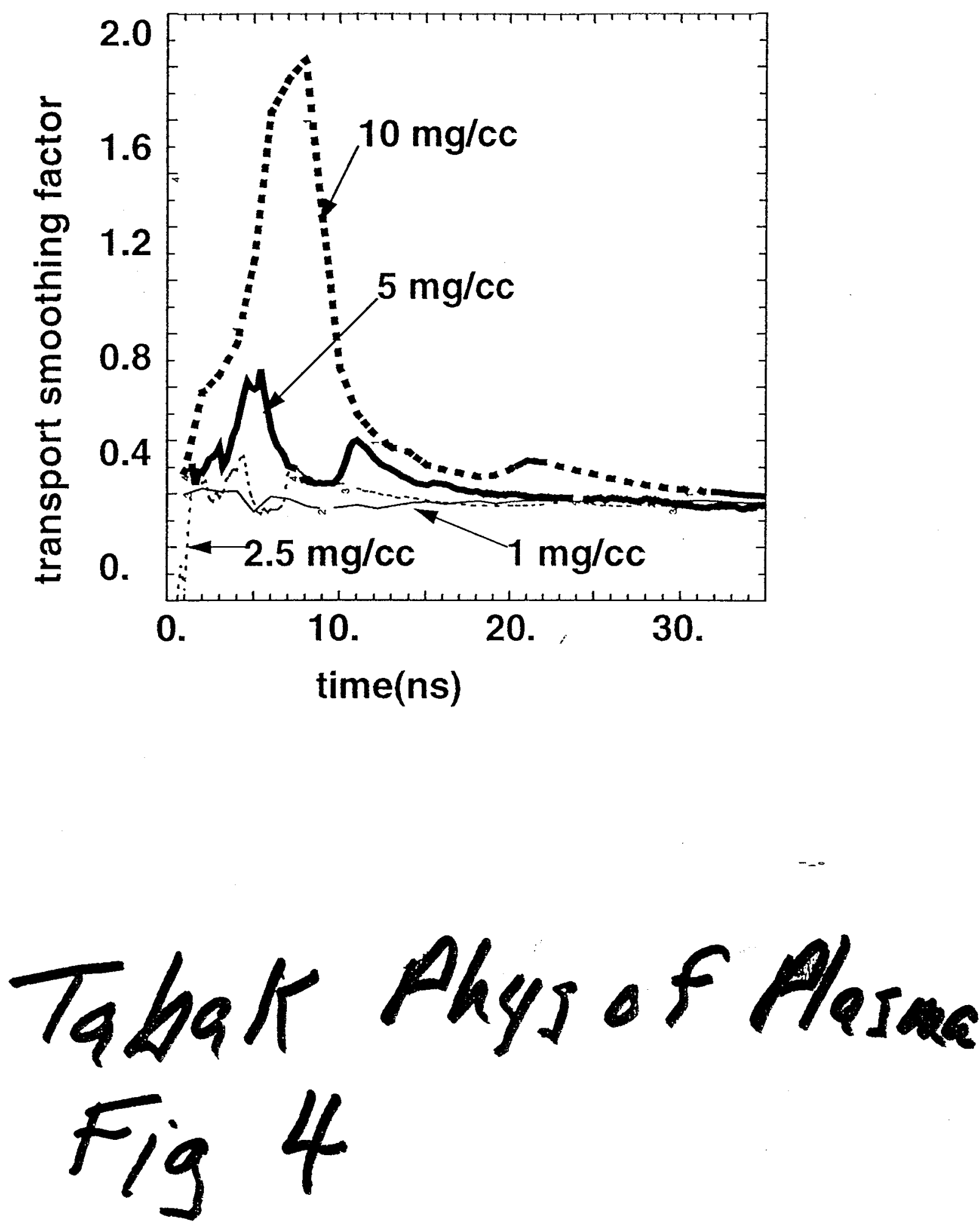


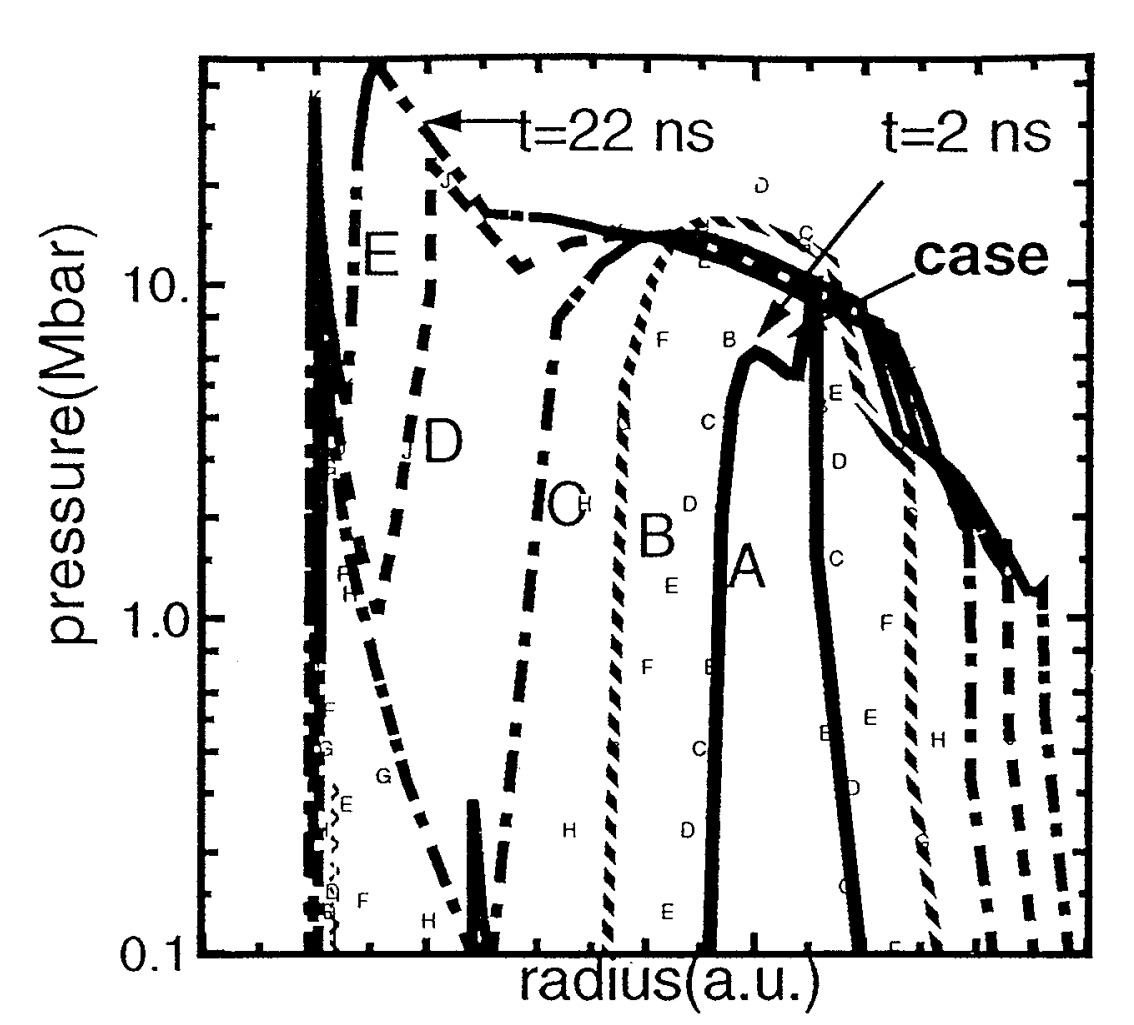

$$
\begin{aligned}
& \text { Tabak Phis of Plasha } \\
& \text { Fig. } 5
\end{aligned}
$$




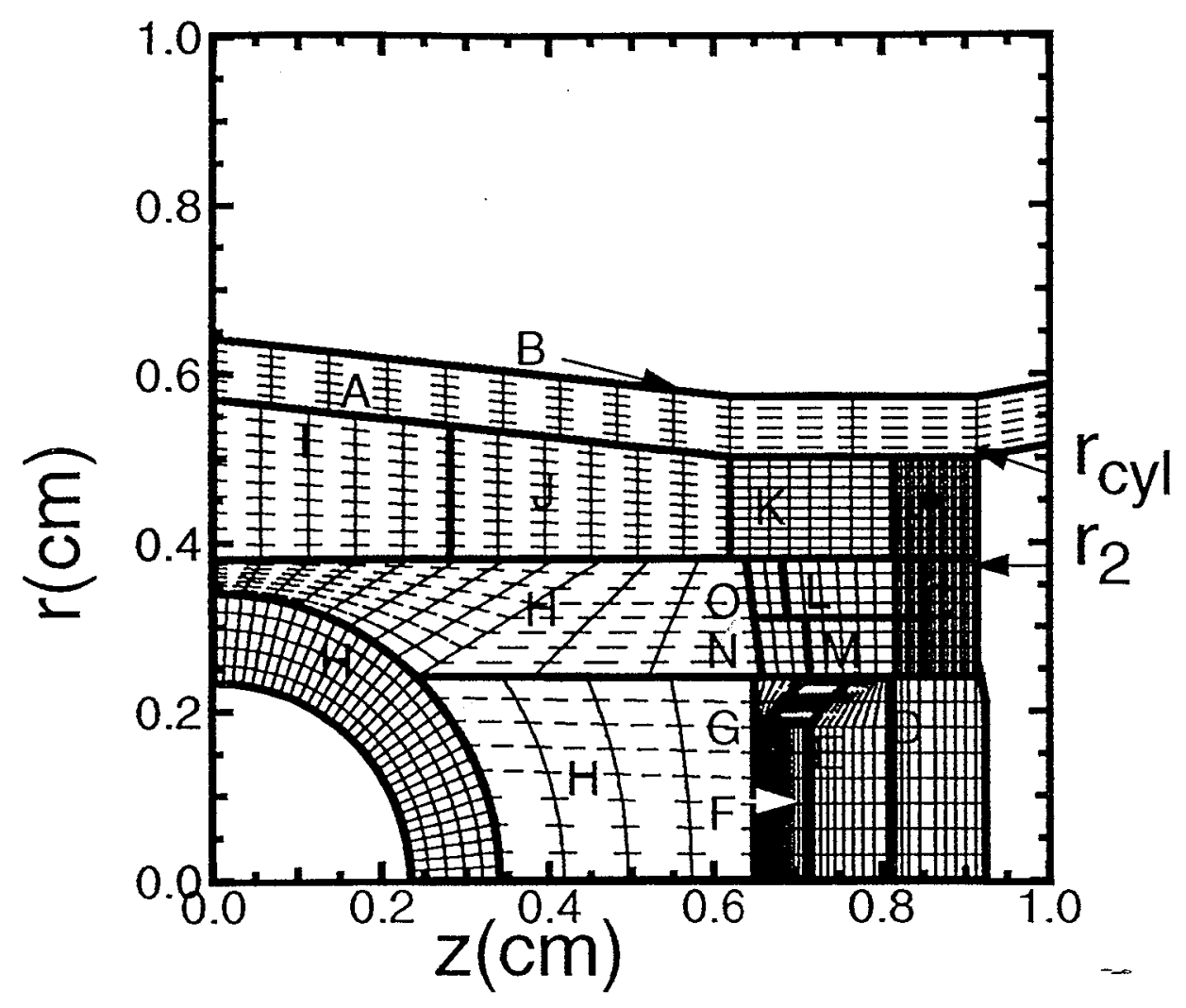

$$
\text { Taball of Plosma }
$$



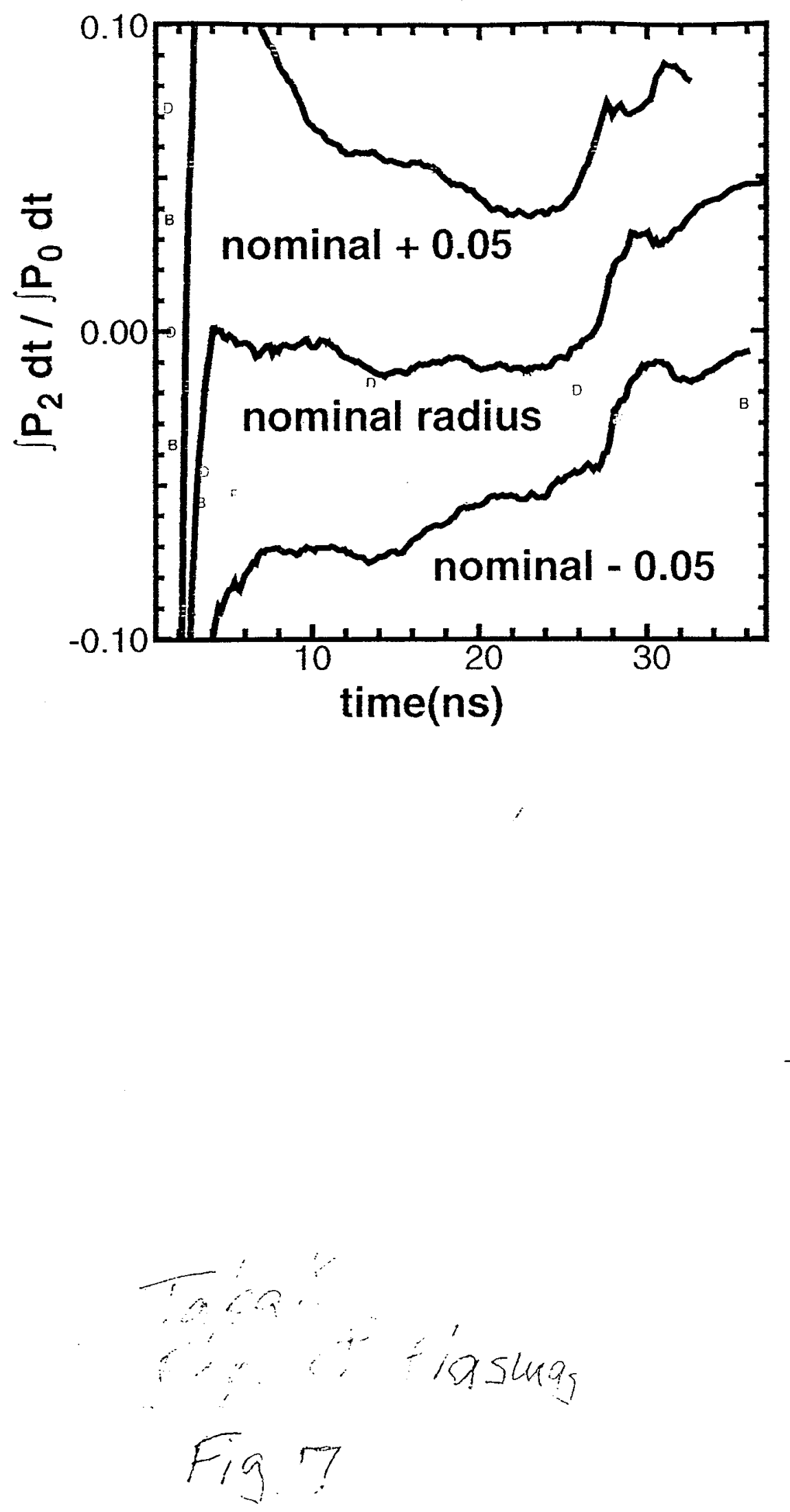


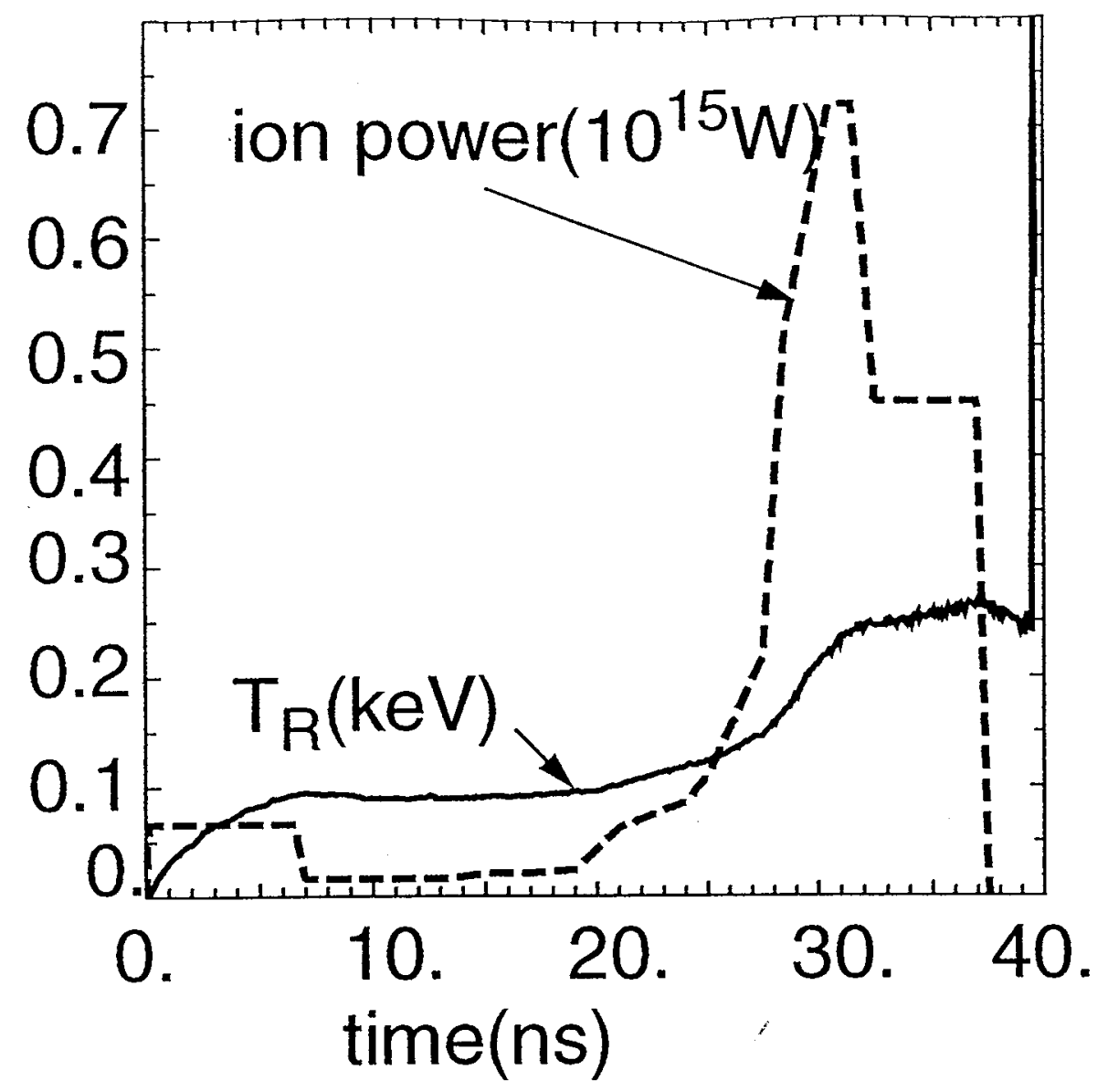

Taha'

Pher Plasmor

10,3 


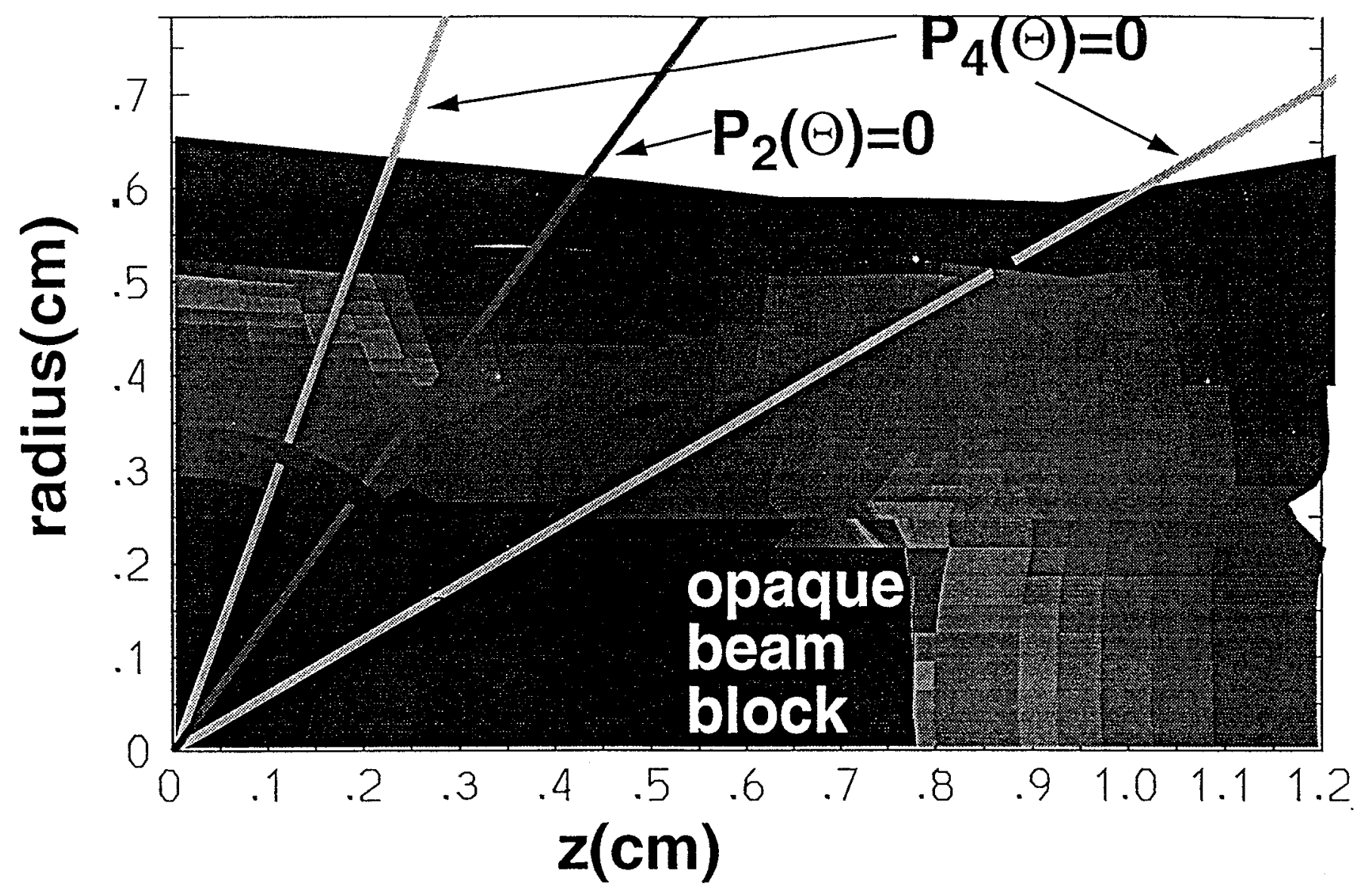

$$
\begin{aligned}
& \text { Tabak } \\
& \text { Fuys of Fosmas } \\
& \text { Fia a }
\end{aligned}
$$




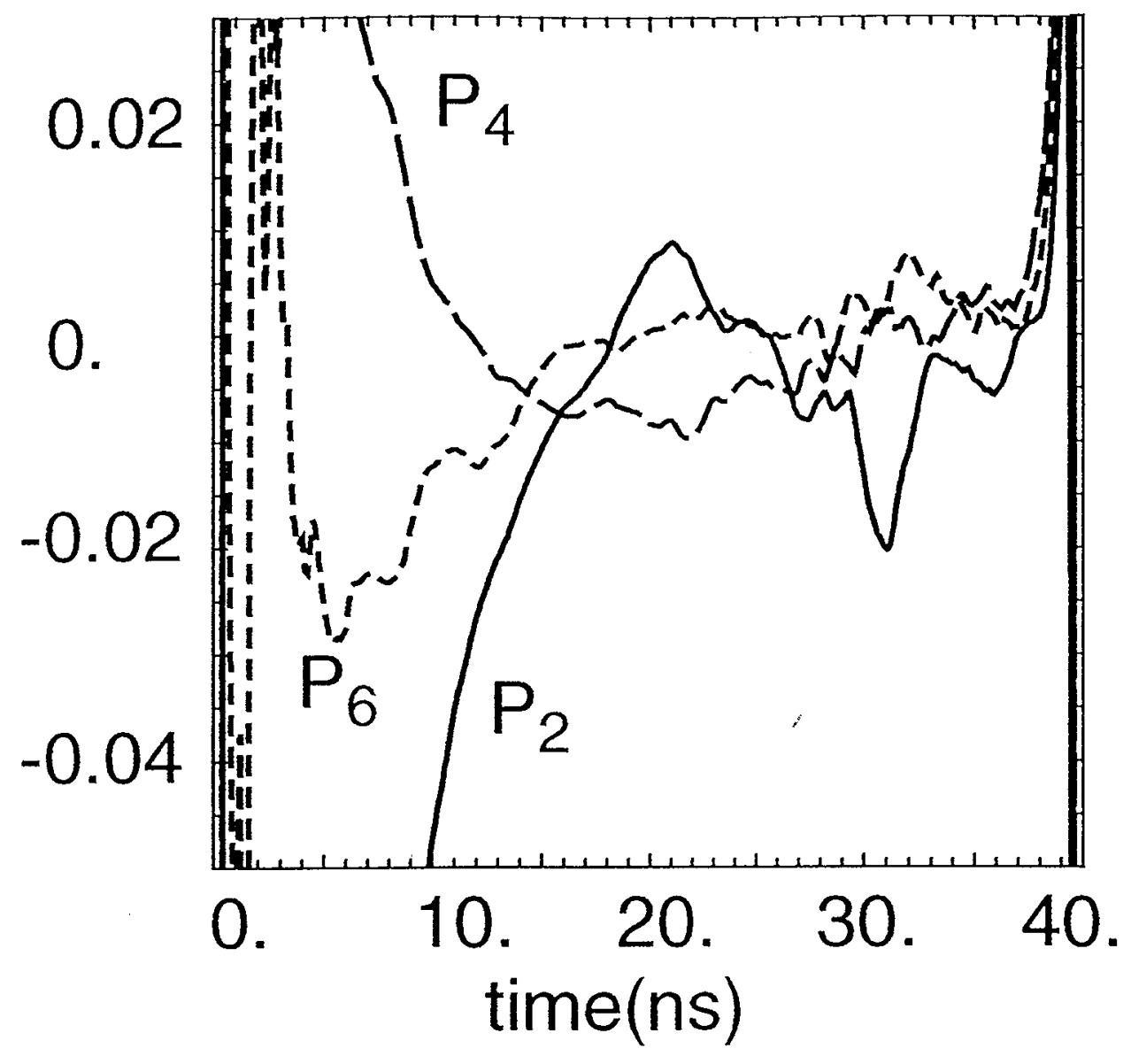

$$
\begin{aligned}
& \text { make flas: } \\
& \text { fays a } 10
\end{aligned}
$$




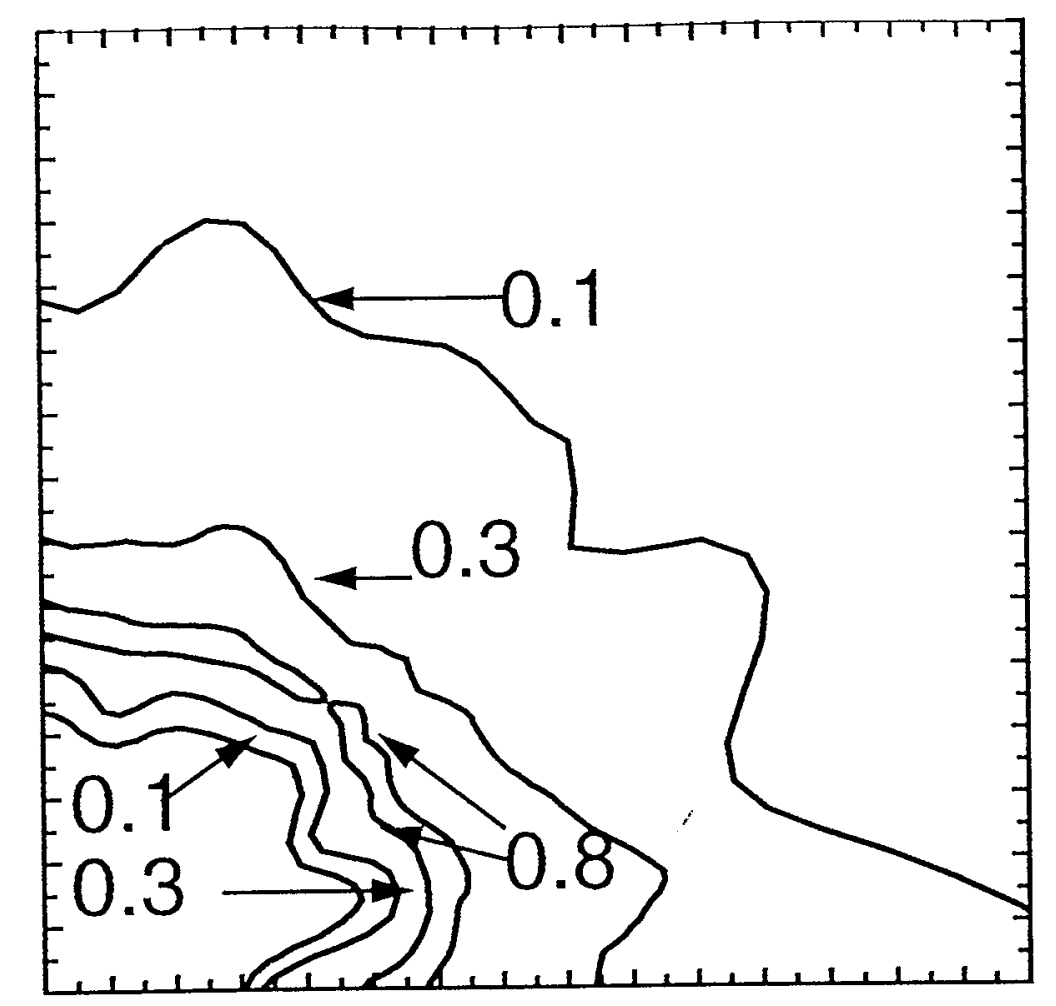

Tabak Phys of Alas ma Fig Ila 

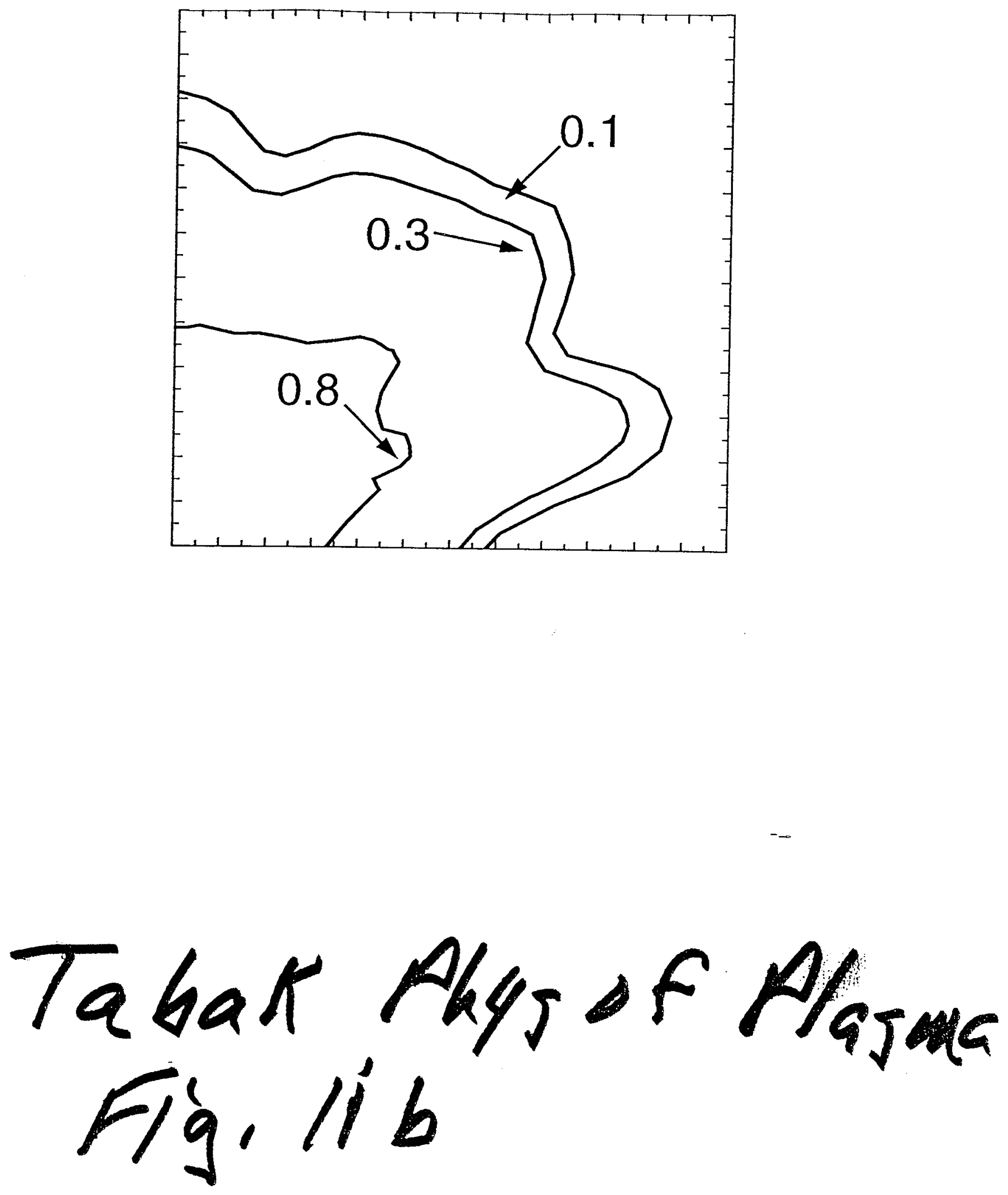


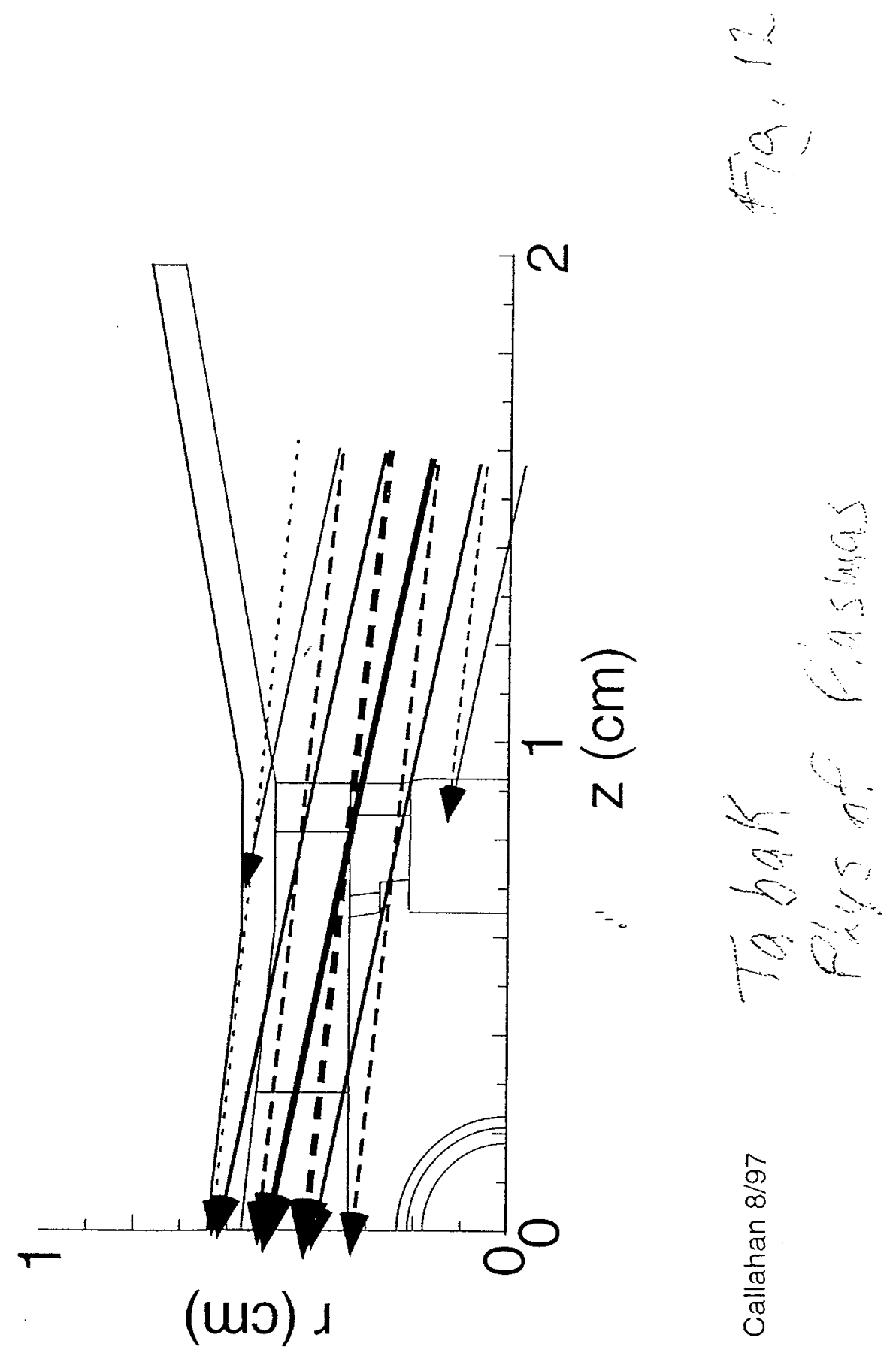




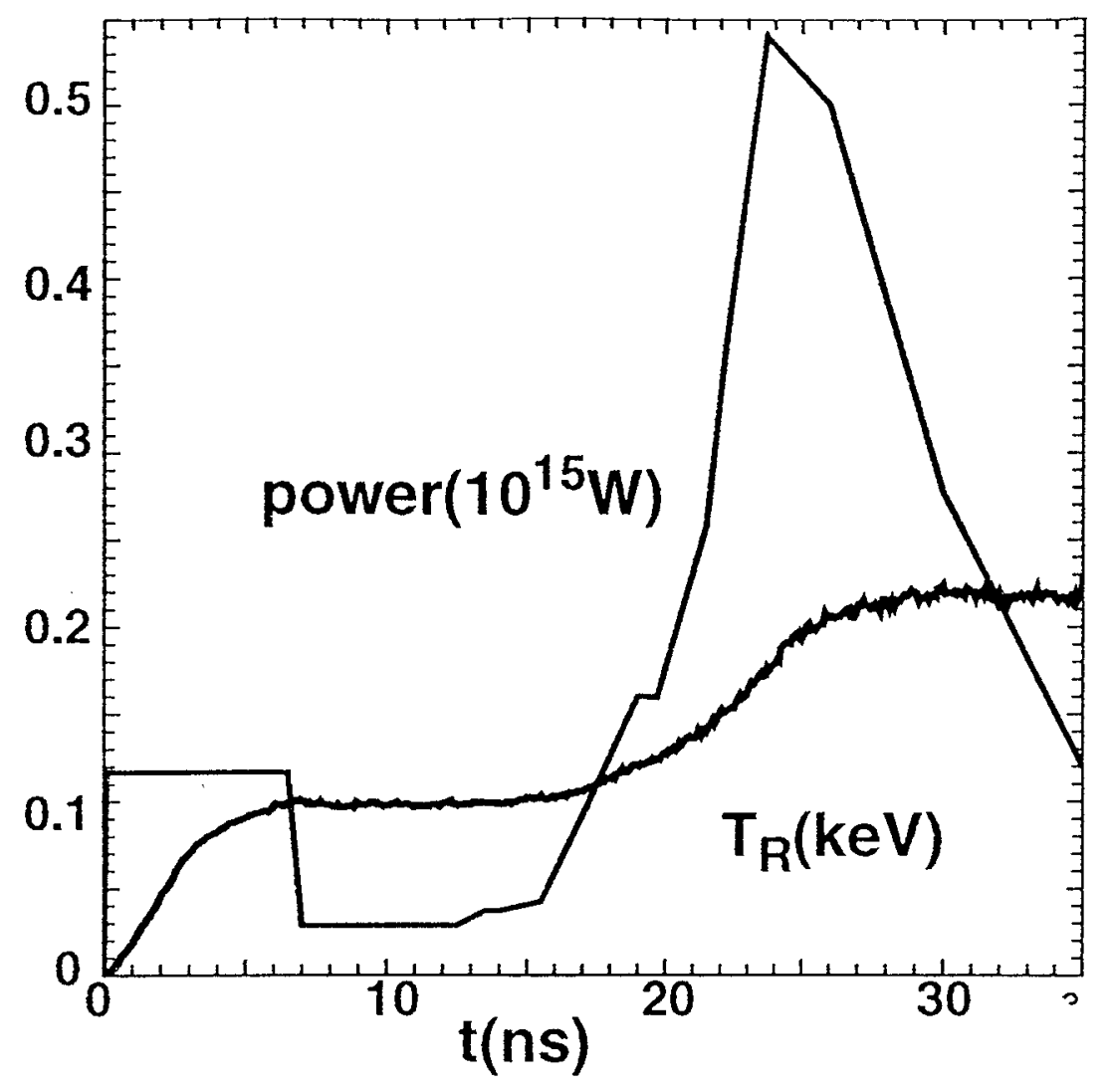

\section{Tabak Physics of Plasmas}

Figure 13 


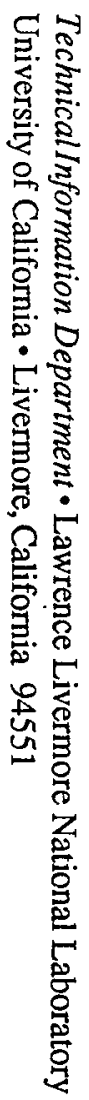

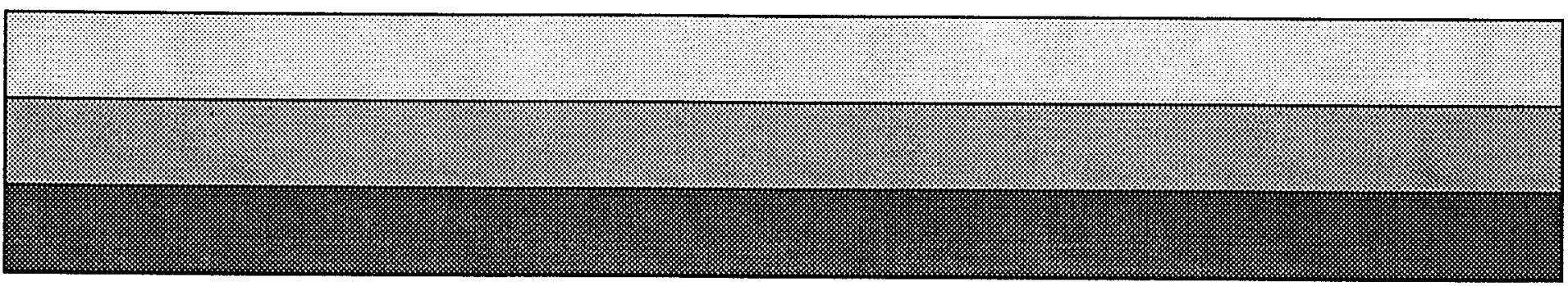

